Archives

16 | 1996

Pour une histoire comparée du vœu

\title{
Pour une histoire comparée du vœu
}

\section{Alain Boureau}

\section{(2) OpenEdition}

Journals

Édition électronique

URL : http://journals.openedition.org/ccrh/2637

DOI : $10.4000 /$ ccrh. 2637

ISSN : $1760-7906$

\section{Éditeur}

Centre de recherches historiques - EHESS

\section{Édition imprimée}

Date de publication : 16 avril 1996

ISSN : 0990-9141

\section{Référence électronique}

Alain Boureau, «Pour une histoire comparée du vœu », Les Cahiers du Centre de Recherches Historiques [En ligne], 16| 1996, mis en ligne le 27 février 2009, consulté le 10 décembre 2020. URL : http:// journals.openedition.org/ccrh/2637 ; DOI : https://doi.org/10.4000/ccrh.2637

Ce document a été généré automatiquement le 10 décembre 2020.

Article L.111-1 du Code de la propriété intellectuelle. 


\title{
Pour une histoire comparée du vœu
}

\author{
Alain Boureau
}

1 Le présent numéro des Cahiers du Centre de recherches historiques présente la plupart des contributions à deux journées d'études sur le vœuํㅜ, organisées en juin 1995 et mai 1996 par Pierre-Antoine Fabre et moi-même. Il ne s'agit pour l'instant que d'une étape dans une recherche collective qui donnera lieu à d'autres rencontres et à une publication plus massive. Mais il nous importait de publier ces textes, qui présentent déjà un panorama suggestif et dont la diffusion suscitera, espérons-nous, d'autres recherches.

Ce travail s'est effectué dans le cadre de la recherche proposée par le CRH sur les phénomènes de conversion. Le vœu religieux, en effet, constitue l'une des institutions de ce que nous appelons la conversion interne, ce mouvement par lequel les fidèles d'une religion entendent affirmer une participation plus directe, plus intense, plus authentique ou plus personnelle à la foi commune. Ainsi, l'entrée au monastère est présentée dans les textes monastiques de l'Occident médiéval comme une conversion qui redouble l'acte initial d'entrée dans le christianisme (le baptême). Et précisément, en ce cas, des vœux (les trois vœux monastiques d'obéissance, de chasteté et de pauvreté) manifestent cette conversion seconde. D'ailleurs, le discours scolastique, en associant le vœu commun, émis par tout chrétien par le biais de ses parents spirituels lors du baptême et le vœu particulier, spécifique à certains états religieux, lie étroitement les deux modes de conversion.

3 L'étude du vœu comme manifestation institutionnelle-monastique-ne saurait intéresser qu'une histoire descriptive de l'Église chrétienne si elle ne posait en fait des questions bien plus générales qui relèvent du droit, de l'histoire et de l'anthropologie. Si l'on retient provisoirement une définition scolastique reprise par saint Thomas (« le vœu est une promesse faite à Dieu »), on en repère immédiatement la riche complexité. Un engagement pris auprès de Dieu, de façon publique ou privée, relève au Moyen Age de la norme, et plus précisément du droit canonique. Charles de Miramon donne ici les éléments essentiels de cette intégration juridique du vœu dans la première scolastique. C'est cette saisine du vœu par le droit qui le construit en objet historique et qui formalise le fait graduellement explicité de l'intégration fonctionnelle des ordres monastiques - principaux producteurs du vœu-dans l'Église universelle. On le sait, les sociétés 
monastiques, durant le premier millénaire, constituent formellement des agrégats dévots et laïcs, avant que l'ordination sacerdotale généralisée n'en fasse une branche de l'Église : les réguliers. On comprend dès lors l'absence de toute théorie du vœu dans les grandes règles monastiques, malgré des reconstructions postérieures. Le moine du Haut Moyen Age obéit certes à son abbé et s'y engage ; mais il ne prononce pas les trois vœux, même si la substance s'en trouve dans les diverses règles. Dès lors, aux XII ${ }^{\mathrm{e}}$ et XIII ${ }^{\mathrm{e}}$ siècles, le vœu devient la charte de chaque ordre et se négocie juridiquement. Il se construit hiérarchiquement : les vœux lâches sont inférieurs à des vœux étroits, ce qui détermine la possibilité ou l'impossibilité de passer d'un ordre vers l'autre. En ce domaine comme en bien d'autres, le jus novum pontifical se fonde sur une régulation des passages, des dispenses et des privilèges ; l'Église gère les relations directes entre Dieu et les fidèles par l'intermédiaire des contentieux inévitables créés par l'entrelacs des engagements. On voit bien les parallèles qui s'établissent avec la société civile : une autorité centrale établit sa puissance par le biais d'un arbitrage entre des fidélités singulières, qu'elle tend à transformer en puissance judiciaire. On voit aussi comment le vœu doit s'analyser en relation avec le serment (engagement pris envers les hommes, mais avec Dieu comme garant ou comme témoin). Le grand ouvrage de Paolo Prodi sur le serment a ouvert bien des voies qu'il faudra suivre ou croiser dans l'analyse du vœu. Mais un schéma global des implications politiques et juridiques du vœu demanderait bien des examens particuliers, tant cette position de l'Église a subi de résistances et de contournements, lorsque les ordres et les groupes chrétiens se multiplient et se diversifient. Pierre-Antoine Fabre s'intéresse aux conditions et aux modalités textuelles de cette diversification dans l'élaboration des règles monastiques de l'Antiquité tardive.

4 L'engagement pris envers Dieu construit une relation non seulement juridique ou institutionnelle, mais proprement religieuse, apparentée au sacrement. Nous avons évoqué plus haut le parallèle explicite avec le baptême ; plus généralement, l'émission de vœux apparaît bien comme le signe d'une chose sacrée, comme une proclamation de foi (ce sont là deux des définitions classiques du sacrement reprises par saint Thomas). De fait, le vœu monastique a fonctionné longtemps comme le pendant monastique du sacrement d'ordre. Certes, la liste des sacrements de l'Église se clôt au XII siècle, mais la théologie en demeure fort controversée jusqu'à la fin du Moyen Age. Un épisode fondamental de cette controverse a été constitué, au milieu du XIII ${ }^{\mathrm{e}}$ siècle, par la mise en place d'une conception contractuelle du sacrement: la causalité du sacrement, selon certains maîtres dominicains et franciscains, se trouve dans un pacte conclu entre Dieu et les hommes, davantage que dans une délégation permanente du pouvoir sacré à l'Église. Cette révolution a eu un écho fort dans la théorie du vœu lisible dans l'œuvre du franciscain Pierre de Jean Olivi ou Olieu (vers 1248-1298), étudiée par plusieurs auteurs dans ce cahier (Maria Teresa Dolso, Sylvain Piron, Olivier Boulnois). C'est à David Burr, grand spécialiste d'Olivi, qui présente ici un texte sur Angelo Clareno, disciple du franciscain, que nous devons une analyse précise et forte du caractère révolutionnaire de la théorie olivienne du vœu, notamment grâce à son livre essentiel Olivi and Franciscan Poverty. The Origins of the Usus Pauper Controversy ${ }^{2}$. À la fin des années 1270, Olivi soulève la question de savoir si l' " usage pauvre » (c'est-à-dire la consommation très restreinte des biens de consommation) fait partie ou non de la règle de saint François. La règle «bullée » de François évitait de désigner formellement les trois vœux classiques des ordres en incluant les exigences d'obéissance, de pauvreté et de chasteté dans un vœu plus général défini par la vie évangélique. Or Olivi affirme que l'usage pauvre, dont le modèle se trouve 
dans l'évangile, fait strictement partie de la règle et doit faire l'objet du vœu franciscain. Cette position suscita des réactions violentes dans l'ordre et provoqua les combats qui aboutirent à la formation du groupe des "spirituels» franciscains, dont certains membres furent persécutés au début du XIV ${ }^{e}$ siècle sous Jean XXII et dont d'autres se séparèrent graduellement de la branche "conventuelle » de l'ordre et formèrent, plus tard, l'Observance franciscaine. Comme l'a bien montré David Burr, le conflit portait moins sur l'enrichissement et l'installation de l'ordre que sur la nature même du vœu religieux. Les adversaires d'Olivi disaient que l'on ne peut émettre un vœu sur une matière indéterminée; or l'usage pauvre dépend, à l'évidence, de conditions externes (l'usage pauvre du vêtement n'est pas le même dans un pays froid ou un pays chaud, etc.). Alors que l'absence de propriété individuelle, le renoncement à la sexualité ou le respect de l'obéissance peuvent être pratiqués de façon certaine et absolue, l'usage pauvre et la vie évangélique ne se déterminent que relativement. Comment s'engager auprès de Dieu dans une relation dont les termes ne sont pas fixés? Mais c'est précisément ce caractère essentiellement indéterminé du vœu qui en fait la valeur aux yeux d'Olivi : car l'homme y manifeste alors sa pleine liberté. Olivier Boulnois montre, dans sa contribution, toute l'ampleur de cette théologie de la liberté, dont Sylvain Piron analyse les implications sur l'éthique économique d'Olivi, paradoxal théoricien du capitalisme marchand (c'est Olivi qui invente le sens actuel du mot «capital»). On comprend aussi toutes les virtualités historiques de cette conception radicalement individuelle du vœu.

Parallèlement à cette vie institutionnelle et théologique du vœu se développent, à partir $d u X I V^{e}$ ou $d u X V^{e}$ siècle, des pratiques purement laïques du vœu. Le chevalier fait un vœu; tant qu'il n'aura pas accompli telle ou telle tâche, il renonce à telle ou telle circonstance de sa vie. L'extension de l'analyse au vœu chevaleresque peut paraître purement analogique, puisque l'engagement n'est plus pris auprès de Dieu. Mais en fait, la structure de comportement est identique; comme dans le domaine religieux, il s'agit d'un engagement facultatif et supplémentaire par rapport aux engagements collectifs manifestés dans les serments ou les règles communes. L'instance divine est alors remplacée par l'instance individuelle, selon un schéma qui rappelle précisément le tournant olivien. Les textes de Jesus Rodriguez Velasco et de Dominique de Courcelles présentent ici les premiers éléments d'une réflexion sur le vœu chevaleresque.

Une autre extension de l'analyse, représentée par la contribution de Véronique Bouillier, ouvre la voie à la comparaison du côté des pratiques de l'hindouisme. Nous voudrions poursuivre résolument dans cette voie, car le vœu est un bon objet de comparaison, tant il constitue à la fois un objet historique ou anthropologique variable et un universel possible, si on le définit comme une norme surérogatoire par rapport aux règles communes, qui entend fonder une excellence des individus ou de groupes limités et qui se noue devant une instance transcendante, divine ou éthique. C'est dire que la présente entreprise doit se poursuivre intensément, avec l'espoir que la présente livraison constitue déjà un véritable cahier des charges. 


\section{NOTES}

1. Marco Bartoli (Rome) a présenté, lors de la deuxième journée (1996), une question inédite de Pierre de Jean Olivi sur le vœu. Comme ce travail encore inachevé doit donner lieu à une publication prochaine, on n'en trouvera pas trace ici, bien que la communication orale ait apporté une riche contribution au débat. Massimiliano Guareschi (Turin) a proposé également d'intéressantes réflexions sur le vœu chez Pierre Lombard et chez Hugues de Saint-Victor, ce travail en cours trouvera sa place dans la publication finale.

2. Philadelphie, University of Pennsylvania Press, 1989, 211 p.

\section{AUTEUR}

\section{ALAIN BOUREAU}

$\mathrm{CRH}$, Paris 